(2) Open Access Full Text Article

REVIEW

\title{
Impact of Secukinumab on Patient-Reported Outcomes in the Treatment of Ankylosing Spondylitis: Current Perspectives
}

This article was published in the following Dove Press journal:

Open Access Rheumatology: Research and Reviews

\author{
Hasan Tahir ${ }^{1,2}$ \\ Arumugam Moorthy (iD ${ }^{3}$ \\ Antoni Chan ${ }^{4}$ \\ 'Royal Free London NHS Trust, London, \\ UK; ${ }^{2}$ Division of Medicine, University \\ College London, London, UK; ${ }^{3}$ University \\ Hospitals of Leicester NHS Trust, \\ Leicester, UK; ${ }^{4}$ Royal Berkshire NHS \\ Trust, Reading, UK
}

\begin{abstract}
Ankylosing spondylitis (AS) is a chronic rheumatic disease involving inflammation of the joints and spine, which carries a substantial, life-long burden for the patient. Secukinumab is a fully human anti-interleukin-17A monoclonal antibody, approved in the USA and EU for the treatment of AS. In this narrative review, we searched PubMed with the aim of consolidating the recent literature regarding the impact of secukinumab on patientreported outcomes in patients with AS. A large clinical trial program has demonstrated the efficacy of secukinumab in relieving the signs and symptoms of AS. Most importantly from a patient perspective, secukinumab has produced improvements in a range of patient-reported outcomes (PROs), including pain, fatigue, quality of life and work productivity, as well as composite measures including patient-reported elements, such as the Bath indices and Assessment of SpondyloArthritis international Society (ASAS) response criteria. Benefits to patients were rapid, and sustained in the long term (up to 5 years). The positive effect of secukinumab was seen regardless of whether patients had previously been treated with antitumor necrosis factor (TNF) therapies. Greater improvements in PROs were associated with patients being anti-TNF-naïve, of a younger age, with shorter disease duration and higher objective measures of inflammation at baseline. The available real-world evidence suggests that the effects of secukinumab on PROs in clinical practice are consistent with those seen in clinical trials, and evidence in a real-world setting continues to be collected.
\end{abstract}

Keywords: ankylosing spondylitis, secukinumab, patient-reported outcomes

\section{Introduction}

Ankylosing spondylitis (AS), also known as radiographic axial spondyloarthritis, is a chronic inflammatory rheumatic disease, characterized by progressive structural damage primarily to the axial skeleton, but it can also involve the hips, shoulders, and peripheral joints. AS is included within the axial spondyloarthritis (axSpA) spectrum, and is distinguished from non-radiographic axial spondyloarthritis (nr-axSpA) by the presence of radiographic evidence of sacroiliitis. ${ }^{1}$ Pain, fatigue and reduced mobility are common symptoms of AS, which combine to have a detrimental impact on patients' quality of life (QoL). AS can also severely limit function in daily life and the ability to work productively. Thus, the foremost aim of treating a patient with AS is to maximize long-term health-related QoL by reducing symptoms and inflammation, preventing progressive structural damage, and preserving normal function. ${ }^{2}$

First-line pharmacological treatment for AS is generally non-steroidal antiinflammatory drugs (NSAIDs). In patients for whom NSAIDs are not sufficiently
Correspondence: Hasan Tahir UK

Email hasan.tahir@nhs.net
Open Access Rheumatology: Research and Reviews 2020:12 277-292 
effective or are poorly tolerated, biologic therapies offer an alternative. ${ }^{2}$ Two classes of biologics are currently approved for use in AS: anti-tumor necrosis factor (TNF) therapies and the anti-interleukin 17A (IL-17A) therapies, such as the first-in-class secukinumab. ${ }^{3}$ The advent of biologic therapies for AS has brought about substantial improvements in QoL for patients. This has been demonstrated through improvements in patient-reported outcomes (PROs). This article reviews the clinical data investigating the efficacy of secukinumab in treating PROs in patients with AS, focusing on pain, fatigue, independence and function.

Articles for this review were identified through searches of PubMed with the search terms "ankylosing spondylitis", "axial spondyloarthritis", "patient-reported outcome" and "secukinumab" from 1966 to March 2020. Articles were also identified through searches of the authors' own files and personal knowledge. Only papers published in English were reviewed. The final reference list utilized was based on originality and relevance to the scope of this review.

\section{Role of Interleukin- I 7A in the Pathogenesis of AS}

Interleukin-17A (IL-17A) is a pivotal cytokine in the pathogenesis of AS, known to play a role in a myriad of AS manifestations, including the cardinal inflammation of the spine, joints and entheses. Indeed, in patients with AS, the number of IL-17-producing cells is significantly raised in the circulation and in key tissues such as the synovial joints. ${ }^{4-6}$ Upon binding to its receptor, IL-17A causes the upregulation of inflammatory gene expression and establishes an inflammatory pathway that ultimately drives joint inflammation, vessel activation, matrix destruction, bone erosion and proliferation and cartilage damage. ${ }^{7,8}$

The bone changes seen in AS are a predominant cause of disability in patients. IL-17A, along with IL-23 and TNF, is an important effector cytokine of enthesitis, and persistent activation of prostaglandin E2 and the IL-23-IL17 axis initiates inflammation of the entheses. ${ }^{9}$ If this inflammation is prolonged, it leads to the characteristic bone damage of AS. It is thought that through stimulating the receptor activator of nuclear factor-kB/RANK ligand/ osteoprotegerin (RANK/RANKL/OPG) pathway, IL-17A promotes osteoclastogenesis, inducing bone erosion. ${ }^{7}$ Furthermore, it is believed that IL-17 instigates new bone formation, sometimes simultaneously to erosion, by augmenting differentiation of osteoblasts from mesenchymal stem cells and thus inducing osteogenesis via the Janus kinase 2/signal transducer and activator of transcription 3 (JAK2/STAT3) signalling pathway. ${ }^{10}$ IL-17A also plays a critical role in chronic pain, a prominent feature of AS. It has been shown to directly modulate inflammatory pain; injection of IL-17 elicits increased excitability of nociceptors and neutrophil recruitment in murine models of arthritis. It is speculated that the acute enhanced hyperalgesia this leads to could be relieved with an anti-IL-17 therapy, illustrating the potential for secukinumab to ameliorate pain in AS. ${ }^{11,12}$ The central role of IL-17A in AS is reflected by the success of anti-IL-17 therapies in repressing disease activity.

\section{Secukinumab}

Secukinumab, an anti-IL-17A monoclonal antibody, has shown significant and sustained efficacy in treating AS across a large Phase 3 clinical development program. Inhibition of IL-17A is currently the only alternative biologic mechanism of action to anti-TNF treatments; secukinumab was the first of this class to be approved for use in AS. Secukinumab is a fully human immunoglobulin G1 (IgG1) monoclonal antibody that selectively binds to IL$17 \mathrm{~A}$, thereby inhibiting its interaction with the IL-17 receptor and inhibiting the subsequent release of proinflammatory cytokines and chemokines and cascade of inflammatory pathways. ${ }^{13,14}$

Secukinumab is approved in the EU and the USA for the treatment of plaque psoriasis, psoriatic arthritis, AS and nr-axSpA. The recommended dosage for AS is 150 mg subcutaneously, once every four weeks ( $\mathrm{q} 4 \mathrm{w}$ ), with loading dosing at Weeks $0,1,2,3$, and $4 \cdot{ }^{13,14}$ In the USA, secukinumab treatment may be initiated with or without loading dosage. In both the EU and USA, the dose may be increased to $300 \mathrm{mg}$ if there is an inadequate clinical response. ${ }^{13,14}$

The efficacy and safety of secukinumab for the treatment of AS has been assessed in several multicenter, phase 3 trials, including five randomized, double-blind trials conducted in patients with AS, known as the MEASURE clinical trial program. This encompasses MEASURE 1-5, including the pivotal studies MEASURE 1 and MEASURE 2, as well as Japan (MEASURE 2J) and China-centric (MEASURE 5) studies (Table 1). ${ }^{15-19}$ Several clinical trials are currently ongoing with secukinumab in AS, including a head-tohead trial with a biosimilar of adalimumab, which was 


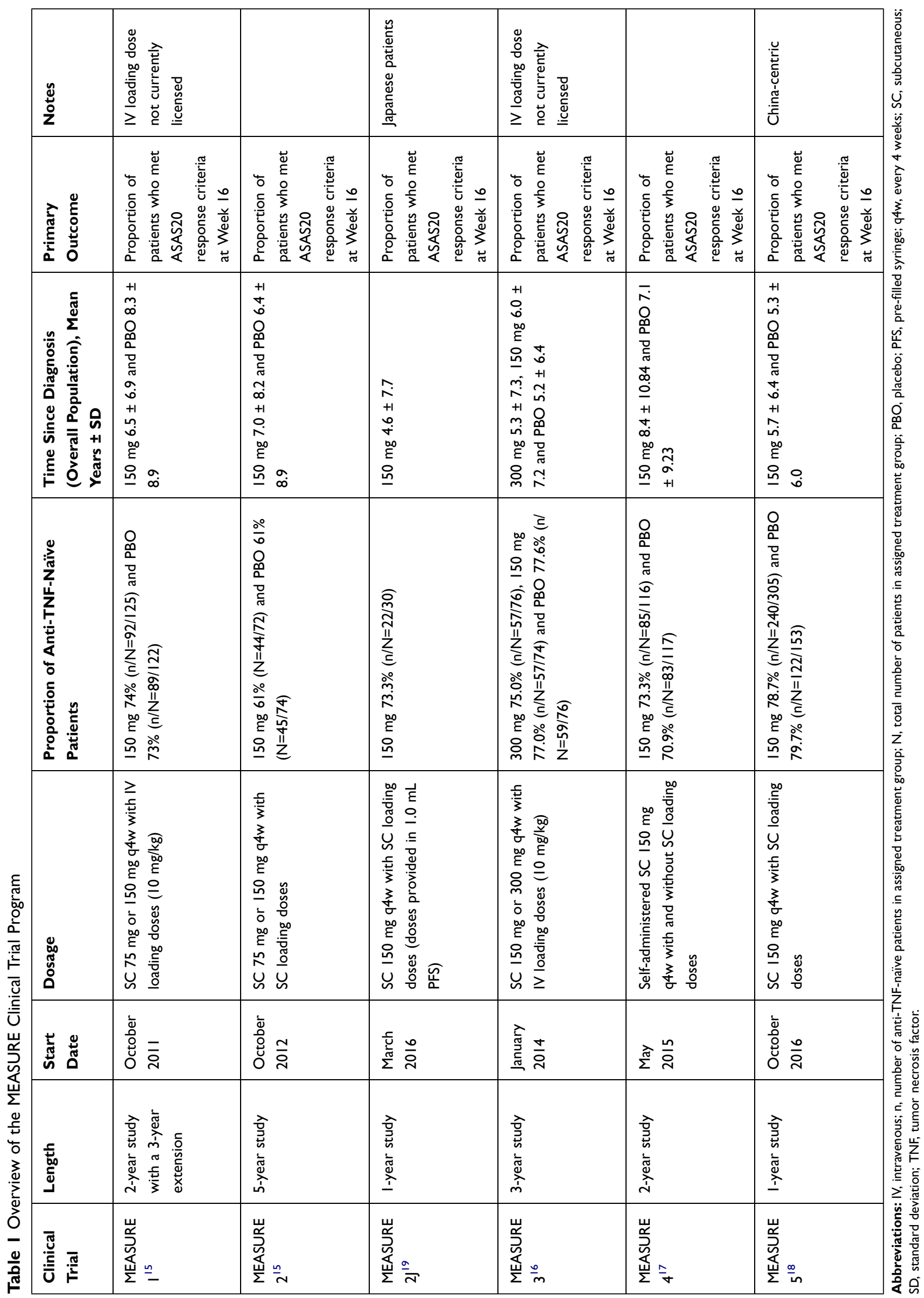


the first fully human anti-TNF-therapy. ${ }^{20}$ Discussion in this review will focus on the approved doses of $150 \mathrm{mg}$ and $300 \mathrm{mg}$, where data are available.

\section{Patient-Reported Outcomes (PROs)}

PROs are of particular importance in chronic diseases, as they are powerful tools to communicate and quantify the patients' experience and suffering. Compared with objective measures assessed by a clinician, PROs give an insight into the most relevant aspects of treatment for patients: those that have a tangible impact on their daily lives. ${ }^{21,22}$ It is therefore not surprising that capturing and monitoring PROs is increasingly being seen as a crucial aspect of AS care, offering an insight into the impact of disease and treatment at the patient level. ${ }^{2,23}$ The Assessment of SpondyloArthritis international Society (ASAS)/Outcome Measures in Rheumatology Clinical Trials (OMERACT) groups have identified fatigue, function, pain, patient global assessment and stiffness as core domains from a research and clinical care perspective in AS, with many of these measures being tracked completely or partially using PROs. ${ }^{24}$ In addition, AS disease activity measures such as the Bath Ankylosing Spondylitis Disease Activity Index (BASDAI), ASAS responses and the Ankylosing Spondylitis Disease Activity Score (ASDAS) are built upon a foundation of PROs; it is therefore not surprising that there is often crossover between the categories of assessment measures. ${ }^{24}$

Many patient-reported measures, or measures containing a patient-reported aspect, have been developed specifically to address patients' wellbeing in AS. A combination of AS-specific assessments and more general measures have been applied in randomized clinical trials (RCTs) to gain a patients' perspective of how effective the treatments being evaluated are. Those discussed here include: Functional Assessment of Chronic Illness Therapy-Fatigue (FACIT-F), a measure of fatigue, ${ }^{25}$ nocturnal and total back pain; ${ }^{26,27}$ Ankylosing Spondyloarthritis Quality of Life (ASQoL); the 36-Item Short Form Survey (SF-36), and EuroQol - 5 Dimension

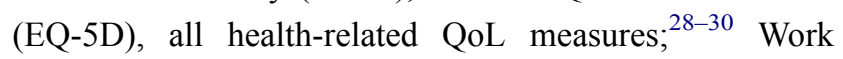
Productivity and Activity Impairment questionnaire (WPAI), designed to measure work productivity and attendance; ${ }^{31}$ the Bath indices, which quantify disease activity, function and mobility, ${ }^{32-34}$ and the ASAS response criteria, a composite measure to determine a patient's response to treatment (Table 2). ${ }^{24}$

\section{Fatigue}

Fatigue is one of the most common and life-limiting symptoms of AS and is therefore a key treatment priority for patients and clinicians, although its relevance is often overlooked when designing clinical trials in $\mathrm{AS}^{35,36}$ FACIT-F is a tool used to assess fatigue and its impact on daily activities and function; ${ }^{25}$ however, relatively few RCTs have used FACIT-F to directly assess fatigue in patients with AS to date.

In the pivotal MEASURE 1 and 2 clinical trials, treatment with secukinumab $150 \mathrm{mg}$ provided rapid and durable improvement in FACIT-F scores, which was evident as early as Week 4 and sustained for up to five years (Table 3 [MEASURE 1 and 2], Figure 1 [MEASURE 1]). 26,37,38 Importantly, in a treatment landscape in which many patients have already had an inadequate response or intolerance to antiTNF therapies, improvements in the FACIT-F score were observed regardless of prior anti-TNF exposure. ${ }^{26}$ In a further analysis of MEASURE 1 and 2 data, patients were categorized as having clinically meaningful improvements in fatigue if they had demonstrated a change in FACIT-F score of $\geq 4$ from baseline. ${ }^{39,40}$ Beginning at Week 4 , a significantly greater proportion of patients treated with secukinumab $150 \mathrm{mg}$ achieved a fatigue response compared with placebo (proportion of patients achieving a fatigue response at Week 16 : MEASURE 1: $66.4 \%$ versus $47.7 \%$; MEASURE 2: $77.6 \%$ versus $50.0 \%, \mathrm{p}<0.05)$, which was sustained through two years (MEASURE $1,71.3 \%$ ). ${ }^{40}$ In this analysis, anti-TNFnaïve patients showed a numerically higher response when the primary efficacy analyses were performed at Week 16, compared with patients who had previously responded inadequately to anti-TNF-therapies (anti-TNF-IR) (MEASURE 1: $68.9 \%$ versus 59.4\%; MEASURE 2: $86.0 \%$ versus $62.5 \%$ ). ${ }^{40}$ The findings from these trials have shown that fatigue, one of the most challenging and impactful symptoms of AS, can be effectively ameliorated with secukinumab.

\section{Pain}

As spinal inflammation is a defining characteristic of AS, back pain is one of the central symptoms. Chronic back pain has a pernicious effect on patients' QoL, and consequently, its treatment is of high concern to patients with $\mathrm{AS}^{41}$ It is routinely measured using a visual analog scale (VAS) as part of the BASDAI (Bath Ankylosing Spondylitis Disease Activity Index) score, which includes a patient-reported assessment of pain in the back, neck and hips. ${ }^{26,27}$ In MEASURE 2, swift reductions in total back pain were seen 
Table 2 Overview of Patient-Reported Outcomes (PROs) Included with Definitions

\begin{tabular}{|c|c|}
\hline PRO & Definition \\
\hline $\begin{array}{l}\text { ASAS (Assessment of SpondyloArthritis } \\
\text { international Society) response criteria }{ }^{27}\end{array}$ & $\begin{array}{l}\text { A composite measure designed to assess response to treatment in AS, including four } \\
\text { domains: patient global assessment, pain assessment, physical function (BASFI) and } \\
\text { inflammation (last two questions of BASDAI) }\end{array}$ \\
\hline ASAS $20^{27}$ & $\begin{array}{l}\text { An improvement of at least } 20 \% \text { and an absolute improvement of at least } 10 \text { units on a I- } \\
100 \text { scale in a least three of the four domains in the ASAS response criteria, with no } \\
\text { worsening of } 20 \% \text { or more or } 10 \text { units or more in the remaining domain }\end{array}$ \\
\hline ASAS40 ${ }^{27}$ & $\begin{array}{l}\text { As above with improvements of at least } 40 \% \text { and an absolute improvement of at least } 20 \\
\text { units, with no worsening at all in the remaining domain }\end{array}$ \\
\hline $\begin{array}{l}\text { ASAS-HI } \\
\text { (ASAS Health Index) }\end{array}$ & $\begin{array}{l}\text { A linear composite measure which includes } 17 \text { items covering most of the International } \\
\text { classification of functioning, disability and health (ICF) core set for AS }\end{array}$ \\
\hline ASQoL ${ }^{28}$ & $\begin{array}{l}\text { Questionnaire to measure AS-specific quality of life (QoL), designed to monitor patients and } \\
\text { evaluate the impact of new treatments and based on a needs-based model of QoL }\end{array}$ \\
\hline $\begin{array}{l}\text { BASDA }^{32} \\
\text { (Bath Ankylosing Spondylitis Disease Activity } \\
\text { Index) }\end{array}$ & $\begin{array}{l}\text { A measure of disease activity consisting of } 10 \mathrm{~cm} \text { VAS (visual analog score) or NRS } \\
\text { (numerical rating scale) in response to six questions on the five major symptoms of AS: } \\
\text { fatigue, spinal pain, joint pain/swelling, areas of localized tenderness, and morning stiffness } \\
\text { (duration and severity). The mean of the two scores relating to morning stiffness is taken, } \\
\text { and the resulting } 0-50 \text { score divided by five to give a final 0-10 BASDAl score }\end{array}$ \\
\hline $\begin{array}{l}\text { BASFI }^{33} \\
\text { (Bath Ankylosing Spondylitis Functional Index) }\end{array}$ & $\begin{array}{l}\text { A measure of functional limitation consisting of } 10 \mathrm{~cm} \text { VAS or NRS answers to } 10 \text { questions, } \\
\text { eight assessing functional anatomy and two relating to the patient's ability to cope with } \\
\text { activities in everyday life }\end{array}$ \\
\hline $\begin{array}{l}\mathrm{BDI}-\mathrm{II}^{67} \\
(\text { Beck Depression Inventory-II) }\end{array}$ & $\begin{array}{l}\text { A measure of the intensity of depression in clinical and normal patients, consisting of } 21 \\
\text { items rated on a 4-point scale, relating to symptoms of depression such as hopelessness, } \\
\text { irritability, fatigue and weight loss. Maximum total score of } 63\end{array}$ \\
\hline $\begin{array}{l}\text { EQ-5D } \\
\text { (EuroQol - } 5 \text { Dimension) }\end{array}$ & $\begin{array}{l}\text { A health-related QoL measure that includes five dimensions: mobility, self-care, usual } \\
\text { activities, pain/discomfort, and anxiety/depression }\end{array}$ \\
\hline $\begin{array}{l}\text { FACIT-F }^{25} \\
\text { (Functional Assessment of Chronic Illness Therapy- } \\
\text { Fatigue) }\end{array}$ & $\begin{array}{l}\text { A measure of fatigue, comprising } 13 \text { items to evaluate an individual's level of fatigue during } \\
\text { their usual daily activities over the past week, measured on a four point Likert scale with a } \\
\text { total score between } 0 \text { and } 52\end{array}$ \\
\hline MOS (Medical Outcomes Study) sleep scale ${ }^{66}$ & $\begin{array}{l}\text { A measure of sleep quality examining six features: initiation and maintenance of sleep, } \\
\text { respiratory problems, quantity and perceived adequacy of sleep, and somnolence }\end{array}$ \\
\hline Morning stiffness ${ }^{26,27}$ & $\begin{array}{l}\text { Based on a mean of the BASDAI questions 'How would you describe the overall level of } \\
\text { morning stiffness you have had from the time you wake up?', with the response given on a } \\
\text { VAS from none to very severe and 'How long does your morning stiffness last from the time } \\
\text { you wake up?', with the response given on a VAS from 0-2 or more hours }\end{array}$ \\
\hline Total and nocturnal back pain ${ }^{26,27}$ & $\begin{array}{l}\text { Based on the BASDAI question 'How would you describe the overall level of AS neck, back } \\
\text { or hip pain you have had?' and the question 'How would you describe the level of AS neck, } \\
\text { back or hip pain you have had at night?', with responses given on a VAS from none to very } \\
\text { severe }\end{array}$ \\
\hline $\begin{array}{l}\text { SF-36 } \\
\text { (Short Form Survey-36) }\end{array}$ & $\begin{array}{l}\text { A survey administered to patients on health-related QoL, containing } 36 \text { questions. It } \\
\text { measures } 8 \text { scales: physical functioning, role physical, bodily pain, general health, vitality, } \\
\text { social functioning, role emotional, and mental health }\end{array}$ \\
\hline
\end{tabular}


Table 2 (Continued).

\begin{tabular}{|l|l|}
\hline PRO & Definition \\
\hline SF-36 MCS $^{30}$ & $\begin{array}{l}\text { The mental component summary (MCS) of the SF-36, measuring the mental dimension of } \\
\text { health; all scales contribute in different proportions to the scoring of the MCS }\end{array}$ \\
\hline SF-36 PCS ${ }^{30}$ & $\begin{array}{l}\text { The physical component summary (PCS) of the SF-36, measuring the physical dimension of } \\
\text { health; all scales contribute in different proportions to the scoring of the PCS }\end{array}$ \\
\hline $\begin{array}{l}\text { WPAl } \\
\text { (Work Productivity and Activity Impairment } \\
\text { questionnaire) }\end{array}$ & $\begin{array}{l}\text { An instrument to measure work productivity and activity impairment. Six questions are } \\
\text { evaluated; each has unique response options, and } 4 \text { outcome scores can be derived (percent } \\
\text { work time missed due to health, percent impairment while working due to health, percent } \\
\text { overall work impairment due to health, and percent activity impairment due to health) }\end{array}$ \\
\hline
\end{tabular}

with secukinumab $150 \mathrm{mg}$ versus placebo; a significant decrease compared with placebo $(\mathrm{p}<0.05)$ was reported after just 1 week of treatment. By Week 16, back pain had decreased by 29.0 points from baseline for patients receiving secukinumab $150 \mathrm{mg}$, compared with a decrease of 11.4 for patients receiving placebo $(\mathrm{p}<0.0001) .{ }^{26}$ Pain relief was maintained through 4 years in both the anti-TNF-naïve and anti-TNF-IR populations. ${ }^{42}$

Back pain in AS typically improves with exercise and is worse at night, so nocturnal back pain is commonly recorded in clinical trials. As has been noted, fatigue is a critical symptom for patients with AS and its impact on patient QoL can be further compounded by nocturnal back pain. Similarly to total back pain, nocturnal back pain was improved in patients in MEASURE 2, and showed rapid and significant improvements with secukinumab $150 \mathrm{mg}$ compared with placebo as early as Week $1(\mathrm{p}<0.001) .{ }^{26}$ At Week 16 in MEASURE 2, patients receiving secukinumab $150 \mathrm{mg}$ had reported a decrease of 30.3 points from baseline for nocturnal back pain, versus a decrease of 10.1 for placebo ( $p<$ $0.0001){ }^{26}$ This improvement was sustained through 4 years, regardless of prior anti-TNF therapy, ${ }^{42}$ although the magnitude of improvement for both total and nocturnal back pain scores was greater in patients who were anti-TNF-naïve. ${ }^{42}$ These data demonstrate secukinumab's proven efficacy in treating back pain in AS, an important PRO.

\section{Morning Stiffness}

Morning stiffness is one of the core domains that ASAS/ OMERACT identify as being important to evaluate in

Table 3 BASDAI, BASFI, SF-36 PCS and FACIT-F versus Placebo at Week 16 in MEASURE $1^{15,38}$ and MEASURE $2^{15,40,82,83}$

\begin{tabular}{|c|c|c|c|c|}
\hline \multirow[t]{2}{*}{ Selected PROs } & \multicolumn{2}{|l|}{ Secukinumab 150 mg } & \multicolumn{2}{|l|}{ Placebo } \\
\hline & MEASURE I $(n=\mid 25)$ & MEASURE $2(n=72)$ & MEASURE I $(n=\mid 25)$ & MEASURE $2(n=74)$ \\
\hline \multicolumn{5}{|l|}{ BASDAI } \\
\hline Baseline & $6.4 \pm 1.6$ & $6.6 \pm 1.5$ & $6.5 \pm 1.5$ & $6.8 \pm 1.3$ \\
\hline Mean change from $B L \pm S D$ & $-2.32 \pm 0.17^{* *}$ & $-2.19 \pm 0.25 * *$ & $-0.59 \pm 0.18$ & $-0.85 \pm 0.25$ \\
\hline \multicolumn{5}{|l|}{ BASFI } \\
\hline Baseline & $5.6 \pm 2.2$ & $6.2 \pm 2.1$ & $5.8 \pm 2.0$ & $6.1 \pm 2.0$ \\
\hline Mean change from $B L \pm S D$ & $-1.8 \pm 0.2^{* * *}$ & $-2.2 \pm 0.2 * * *$ & $-0.4 \pm 0.2$ & $-0.4 \pm 0.2$ \\
\hline \multicolumn{5}{|l|}{ SF-36 PCS } \\
\hline Baseline & $36.8 \pm 6.8$ & $34.4 \pm 6.5$ & $36.3 \pm 6.4$ & $36.3 \pm 6.2$ \\
\hline Mean change from $B L \pm S D$ & $5.6 \pm 0.6 * *$ & $6.1 \pm 0.8 * *$ & $1.0 \pm 0.6$ & $1.9 \pm 0.8$ \\
\hline \multicolumn{5}{|l|}{ FACIT-F } \\
\hline Baseline & $25.6 \pm 10.7$ & $22.6 \pm 8.7$ & $24.5 \pm 9.4$ & $24.3 \pm 9.0$ \\
\hline Mean change from $B L \pm S D$ & $6.8 \pm 0.8 * *$ & $8.1 \pm 1 . I^{*}$ & $2.5 \pm 0.9$ & $3.3 \pm 1.1$ \\
\hline
\end{tabular}

Notes: ${ }^{*} \mathrm{p}<0.01,{ }^{* *} \mathrm{p}<0.001$, ***p $<0.0001$ versus placebo. Data are reported as LSM change from BL using MMRM.

Abbreviations: BASDAI, Bath Ankylosing Spondylitis Disease Activity Index; BASFI, Bath Ankylosing Spondylitis Functional Index; BL, baseline; FACIT-F, Functional Assessment of Chronic Illness Therapy-Fatigue; LSM, least squares mean; MMRM, mixed-model repeated measures; PROs, patient-reported outcomes; SD, standard deviation; SF-36 PCS, Short Form Survey-36 physical component summary. 

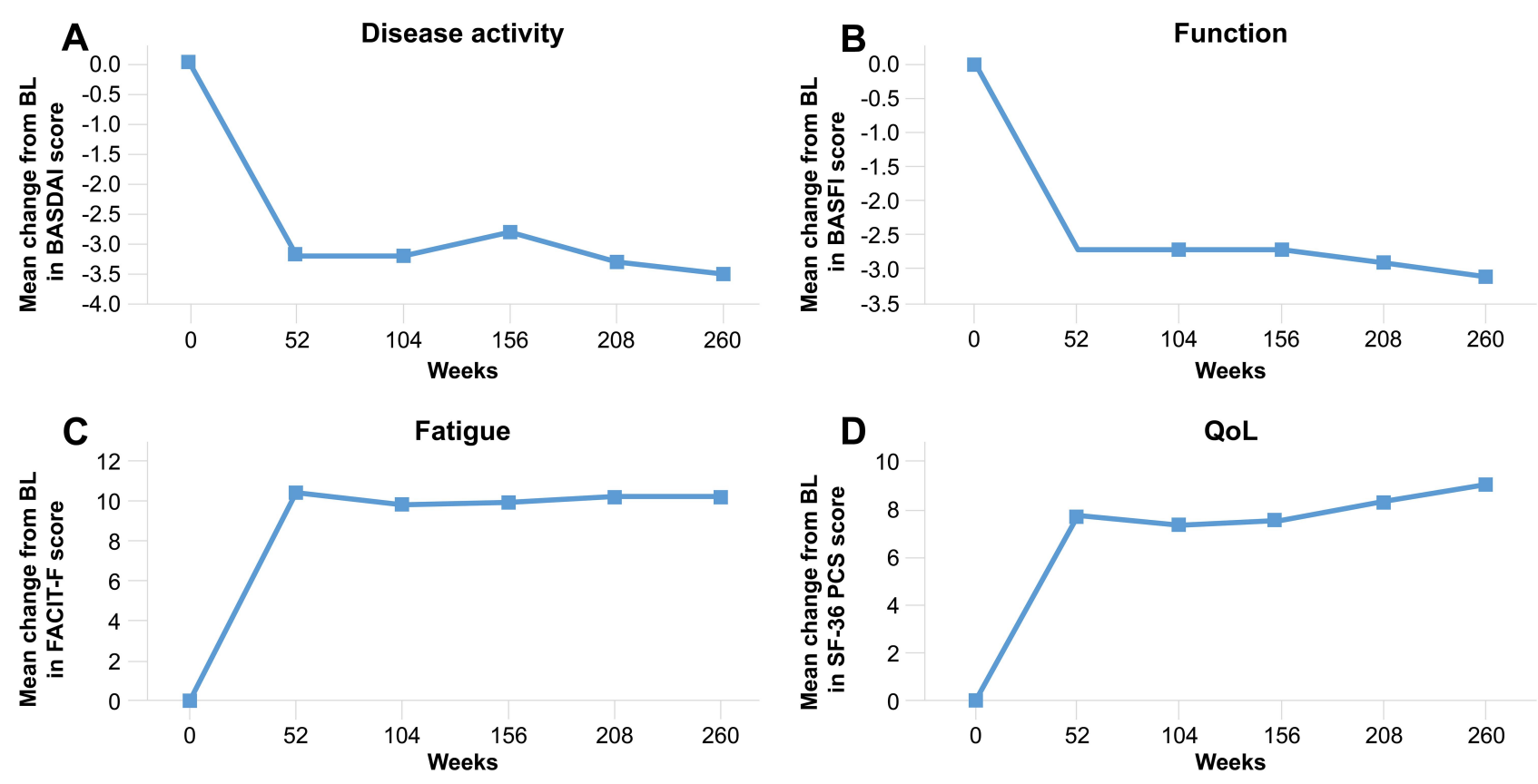

Figure I BASDAI (A), BASFI (B), FACIT-F (C) and SF-36 PCS (D) scores with secukinumab $150 \mathrm{mg}$ through 5 years (MEASURE I) ) $^{37}$ Total number of patients includes placebo switchers. Data shown are as observed through 5 years for patients who entered the three-year extension study after the initial two-year study. Abbreviations: BASDAl, Bath Ankylosing Spondylitis Disease Activity Index; BASFI, Bath Ankylosing Spondylitis Functional Index; FACIT-F, Functional Assessment of Chronic Illness Therapy-Fatigue; SF-36 PCS, Short Form Survey-36 physical component summary.

patients with $\mathrm{AS}^{24}$ and there are data demonstrating a beneficial effect of secukinumab on this important aspect of disease. ${ }^{42}$ In an exploratory analysis using observed data from MEASURE 2, improvements in overall morning stiffness (assessed using an average of questions 5 and 6 on the BASDAI) were seen at Week 4 with secukinumab $150 \mathrm{mg}$ versus placebo were seen at Week 4 ( -2.24 change from baseline versus -0.96 , respectively) and Week 16 $(-2.46$ versus -0.86$) .{ }^{42}$ This translated into a higher proportion of patients achieving a clinically meaningful change in morning stiffness (defined as a $\geq 22.5 \%$ change from baseline) with secukinumab $150 \mathrm{mg}(62.7 \%)$ than placebo (32.8\%) at Week $16 .{ }^{42}$ Improvements with secukinumab were sustained at 4 years $(-3.32$ unit change from baseline; clinically meaningful improvement reported in $77.2 \%$ of patients). ${ }^{42}$

Improvements in morning stiffness were greater than placebo regardless of previous exposure to anti-TNF therapy, although the magnitude of improvement was higher in antiTNF-naïve patients. ${ }^{42}$ At Week 16, a -3.03 unit change from baseline was observed in secukinumab-treated anti-TNFnaïve patients versus -1.15 with placebo, while in antiTNF-IR patients, changes from baseline were -1.44 and -0.31 , respectively. ${ }^{42}$ Clinically meaningful improvements were observed in $67.4 \%$ of anti-TNF-naïve patients receiving secukinumab (versus $35.7 \%$ with placebo) and $54.2 \%$ of
anti-TNF-IR patients (versus $27.3 \%$ with placebo). ${ }^{42}$ By Year 4, the mean change from baseline with secukinumab was -3.69 in anti-TNF-naïve patients and -2.53 in anti-TNFIR patients, with $79.5 \%$ and $72.2 \%$, respectively, reporting clinically meaningful improvement. ${ }^{42}$

\section{Quality of Life (QoL)}

Maintaining independence and function is a priority for patients with AS, as these factors greatly influence their QoL. ${ }^{43}$ Chronicling a patient's outlook on their general wellbeing using a comprehensive QoL measure can help gauge the tangible improvements in their independence and function with treatment. Numerous different tools exist to assess QoL in patients with AS, including disease specific indices such as the ASQoL scale and general tools such as SF-36 and EQ-5D. ASQoL is scored on a scale of $0-18$, and was designed to monitor patients' symptoms and measure the effect of new treatments on their QoL, from their perspective. ${ }^{28}$ According to the mean change from baseline in ASQoL score, secukinumab $150 \mathrm{mg}$ significantly improved patients' QoL by Week 16 of treatment compared with placebo (MEASURE 1: -3.58 versus $-1.04, \mathrm{p}<0.001$; MEASURE 2: -4.00 versus $-1.37, \mathrm{p}<$ 0.01). ${ }^{15}$ These improvements were sustained over 2 years, with mean change of -4.4 seen in patients receiving secukinumab $150 \mathrm{mg}$ (MEASURE 1). ${ }^{44}$ 
Non-disease specific questionnaires can also be used to assess the impact of AS on QoL, for example, the SF-36 questionnaire, which has a physical component summary (PCS) and a mental component summary (MCS), quantifying the effects of treatment on the physical and mental aspects of health, respectively. ${ }^{30}$ Significant improvements in SF-36 PCS scores were observed with secukinumab 150 mg versus placebo in both MEASURE 1 and MEASURE 2 (Table 3), and improvements were sustained over 5 years (MEASURE 1; Figure 1). ${ }^{37}$ Although statistically significant improvements in mental health have not been reported for secukinumab in the treatment of AS, clinically meaningful improvements were observed with secukinumab $150 \mathrm{mg}$ compared with placebo in the MCS, exceeding the minimum clinically important difference (MCID), defined as improvement of $\geq 2.5$ points. ${ }^{38}$ This improvement was maintained over 2 years. ${ }^{44}$ In a pooled analysis of data from MEASURE 1,2 and 4 to examine the clinically meaningful impact of secukinumab on patients' physical and mental QoL, patients were classified as PCS and MCS responders if they met or exceeded the MCID. This analysis showed a significantly higher proportion of patients receiving secukinumab $150 \mathrm{mg}$ versus placebo had clinical meaningful improvements in SF-36 PCS at Week $16(71.4 \%$ versus $46.6 \%, \mathrm{p}<0.0001) .{ }^{45}$ The data also suggested an improvement in patients' mental health, as a numerically greater proportion of the secukinumab $150 \mathrm{mg}$ group versus the placebo group had clinically meaningful improvements in SF-36 MCS at Week 16 (53.7\% versus $47.9 \%$ ), but this difference did not reach statistical significance. ${ }^{45}$ These improvements were consistent in patients who were anti-TNF-naïve and those who were anti-TNF-IR, although responses were more prominent in anti-TNF-naïve patients. Changes in the SF-36 PCS and MCS were sustained across 52 weeks. ${ }^{38,45}$

Lastly, the EQ-5D is another instrument for measuring general health status. It is categorized into five dimensions: mobility, self-care, usual activities, pain/discomfort and anxiety/depression, which are crucial to the independence and function valued by patients with $\mathrm{AS}^{29}$ Secukinumab $150 \mathrm{mg}$ provided improvement in all five domains of health status compared with placebo. A mean change from baseline to Week 16 of 13.3 was observed in patients receiving secukinumab $150 \mathrm{mg}$, compared with 2.0 for patients receiving placebo $(\mathrm{p}<0.0001)$ in MEASURE 1. At Week 52 this improvement was preserved, with a mean change from baseline of 16.4 in those receiving secukinumab $150 \mathrm{mg}{ }^{38}$
Taken together, these data showed improvements in patients' QoL with secukinumab across both AS-specific and general measures. These improvements were sustained over time, suggesting secukinumab has a lasting beneficial impact on patients' QoL, enhancing their day-to-day life.

\section{Work Productivity and Activity Impairment}

Due to the progressive disability incurred by AS, the work productivity of patients with AS is often negatively affected, impeding their ability to partake in active employment and frequently leading to premature retirement from the workforce, a crucial factor in maintaining normal levels of independence and function. ${ }^{46}$ Impairment at work is of particular relevance in treating AS, as patients are often diagnosed in their $20 \mathrm{~s}$ and $30 \mathrm{~s}$, an age when they are typically most productive at work. ${ }^{47,48}$ To evaluate the impact of AS on work, the Work Productivity and Activity Impairment questionnaire (WPAI) is often used, which is a composite score derived from four outcome measures: presenteeism (impairment at work), activity impairment, absenteeism (work time missed) and overall work impairment. ${ }^{31}$ Secukinumab 150 mg was associated with percentage improvements across all four domains of WPAI from baseline to Week 16 (Table 4), ${ }^{38}$ suggesting patients receiving secukinumab $150 \mathrm{mg}$ were able to increase their productivity at work, although these changes were not significant compared with placebo. These changes were sustained or further improved up to 2 years in MEASURE 1 and 1 year in MEASURE 2, regardless of prior anti-TNF exposure. ${ }^{49}$

\section{Disease Activity (BASDAI)}

The Bath Ankylosing Spondylitis Disease Activity Index (BASDAI) is a composite index that reports patients' responses to questions pertaining to the five core symptoms of AS, giving a patient's perspective of their current disease activity. It is measured on a $0-10 \mathrm{~cm}$ VAS, and relates to: fatigue, spinal pain, joint pain/swelling, areas of localized tenderness and morning stiffness. ${ }^{32,50}$ Treatment with secukinumab has been proven to reduce disease activity, according to the patient-reported BASDAI score, across the MEASURE clinical trial program. BASDAI scores were significantly improved in patients receiving secukinumab $150 \mathrm{mg}$ versus placebo at Week 16 in MEASURE 1 and 2 $(\mathrm{p}<0.001$; Table 3$) .{ }^{15}$ Disease activity was continuously suppressed through 5 years of treatment with secukinumab $150 \mathrm{mg}$ (MEASURE 1; Figure 1), regardless of previous 
Table 4 Change from BL in WPAl Domains at Week 16 (MEASURE I)

\begin{tabular}{|c|c|c|}
\hline WPAI Domains & $\begin{array}{l}\text { Secukinumab I50 } \\
\text { mg }\end{array}$ & Placebo \\
\hline \multicolumn{3}{|l|}{ Absenteeism } \\
\hline $\begin{array}{l}\text { Baseline } \\
\text { Change from BL }(\% \pm \\
\text { SEM) }\end{array}$ & $\begin{array}{l}11.6 \pm 21.6 \\
-1.0 \pm 21.5\end{array}$ & $\begin{array}{r}15.3 \pm 25.7 \\
+1.9 \pm 22.4\end{array}$ \\
\hline \multicolumn{3}{|l|}{ Impairment at work } \\
\hline $\begin{array}{l}\text { Baseline } \\
\text { Change from BL }(\% \pm \\
\text { SEM) }\end{array}$ & $\begin{array}{l}45.3 \pm 24.1 \\
-20.1 \pm 24.8\end{array}$ & $\begin{array}{l}51.7 \pm 18.7 \\
-12.8 \pm \\
26.0\end{array}$ \\
\hline \multicolumn{3}{|l|}{ Activity impairment } \\
\hline $\begin{array}{l}\text { Baseline } \\
\text { Change from BL }(\% \pm \\
\text { SEM) }\end{array}$ & $\begin{array}{l}56.7 \pm 23.9 \\
-18.7 \pm 25.9\end{array}$ & $\begin{array}{l}58.9 \pm 21.3 \\
-7.0 \pm 27.2\end{array}$ \\
\hline \multicolumn{3}{|c|}{ Overall work impairment } \\
\hline $\begin{array}{l}\text { Baseline } \\
\text { Change from BL }(\% \pm \\
\text { SEM) }\end{array}$ & $\begin{array}{l}49.7 \pm 26.2 \\
-20.8 \pm 26.1\end{array}$ & $\begin{array}{l}56.7 \pm 19.8 \\
-10.2 \pm \\
27.0\end{array}$ \\
\hline
\end{tabular}

Notes: No changes in WPAI domains were statistically significant versus placebo at Week 16. Data reported as observed mean change from BL. Reproduced with permission of Deodhar AA, Dougados M, Baeten DL, et al. Effect of Secukinumab on Patient-Reported Outcomes in Patients With Active Ankylosing Spondylitis: A Phase III Randomized Trial (MEASURE I). Arthritis \& Rheumatology 2016. Published by Wiley Periodicals, Inc. on behalf of the American College of Rheumatology. ${ }^{38}$ Abbreviations: BL, baseline; SEM, standard error of the mean; WPAI, Work Productivity and Activity Impairment questionnaire.

exposure to anti-TNF therapies. ${ }^{37}$ Moreover, $53 \%$ of patients receiving secukinumab $150 \mathrm{mg}$ in MEASURE 2 attained BASDAI 50, defined as a $50 \%$ improvement of the baseline BASDAI score and seen as a major clinical response in $\mathrm{AS},{ }^{50}$ at Year 5 (56.1\% anti-TNF-naïve; 46.2\% anti-TNF-IR), showing the potency and durability of patients' response to secukinumab treatment. ${ }^{51}$ For patients receiving the higher dose of secukinumab $300 \mathrm{mg}$ in MEASURE 3, the BASDAI score decreased by an average of 2.7 from baseline, compared with 2.3 for patients receiving $150 \mathrm{mg}$ and 1.5 for patients receiving placebo (both $\mathrm{p}<0.05$ versus placebo). ${ }^{16}$ Improvements were also consistent through 3 years of treatment with secukinumab $300 \mathrm{mg}$ (MEASURE 3). After 3 years of secukinumab treatment, improvement in the BASDAI score was still greater with secukinumab $300 \mathrm{mg}$ compared with $150 \mathrm{mg}(-3.56$ versus -2.76$) .{ }^{52}$

\section{Function (BASFI)}

Many patients with AS suffer with reduced functionality that can often have a severe impact on their daily life and prevent them from carrying out simple physical activities. The Bath Ankylosing Spondylitis Functional Index (BASFI), comprises 10 questions, which were selected with substantial input from patients with AS, to accurately capture the degree of functional limitation according to the patients' experience. ${ }^{53}$ In MEASURE 1, patients receiving secukinumab $150 \mathrm{mg}$ reported significantly improved BASFI scores at Week 16 when compared with patients receiving placebo $(p<0.0001$; Table 3$) .{ }^{54}$ The positive effects of secukinumab treatment on patients' daily activities were maintained in the long term, irrespective of previous exposure to anti-TNF therapies (MEASURE 1; Figure 1$)^{37}$

\section{ASAS Response Criteria}

Originally developed in 2001, the ASAS response criteria were proposed as a short-term improvement criteria to assess patients' response to biologics. ${ }^{55}$ They are primarily objective outcome measures, but as some aspects are patient-reported, including some of the aforementioned indices, they are discussed in this review. The criteria encapsulate the core outcomes of AS treatment, providing a simplified interpretation by classifying each patient as a responder or non-responder and therefore assessing if the treatment is having a significant impact on patients. They are a composite of four domains: patient global assessment, pain assessment, function (BASFI) and inflammation (the last two questions of BASDAI). ASAS20 improvement is defined as an improvement of at least $20 \%$ and an absolute improvement of at least 10 units on a 0-100 scale in at least three of the domains. ${ }^{55}$ ASAS40, a more clinically relevant response, is defined as an improvement of at least $40 \%$ and an absolute improvement of at least 20 units on a $0-100$ scale in at least three of the four domains. ${ }^{56}$

ASAS20 response rates were significantly improved with secukinumab $150 \mathrm{mg}$ compared with placebo across all MEASURE clinical trials (Figure 2). ${ }^{15,16,17}$ The clinical response was significant versus placebo by Week 1 in MEASURE $1(\mathrm{p}<0.01)$ and MEASURE $2(\mathrm{p}<0.05)$, increased at the primary endpoint of Week 16 (MEASURE 1 and $2, \mathrm{p}<0.001$ ), and has been consistent over 5 years (Figure 3). ${ }^{15,37}$ With the higher secukinumab 300-mg dose trialled in MEASURE 3, 60.5\% of patients achieved ASAS20 at Week 16 ( $p<0.01$ versus placebo), compared with $58.1 \%$ of patients receiving secukinumab $150 \mathrm{mg}(\mathrm{p}$ $<0.05$ versus placebo) and $36.8 \%$ of patients receiving placebo. ${ }^{16}$ This response was maintained over 3 years in 


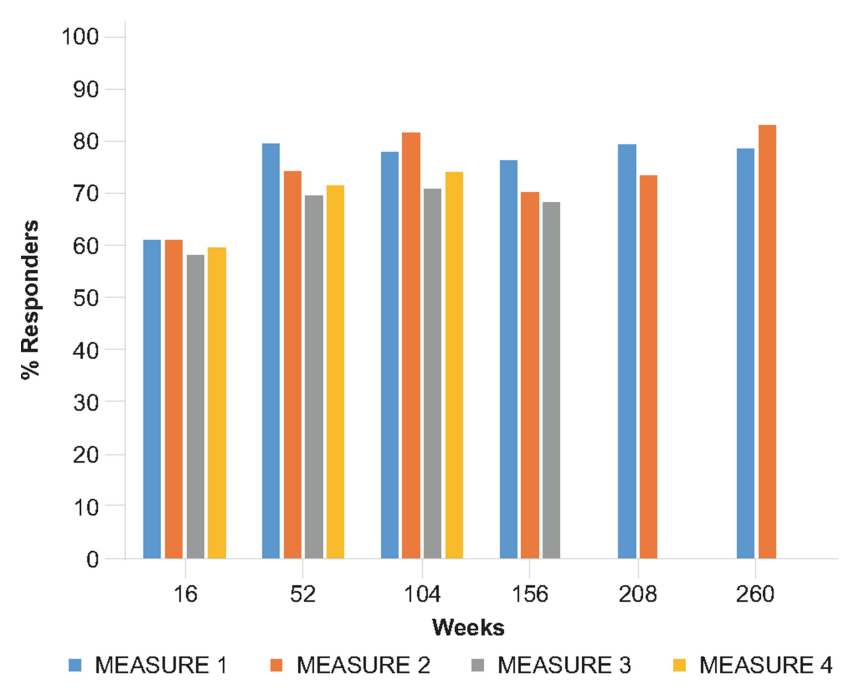

Figure 2 ASAS20 response rates with secukinumab $150 \mathrm{mg}$ treatment across the MEASURE clinical trial program through 5 years. ${ }^{15-17,37,52,53,81,82,80}$ MEASURE I and 3 data include an IV loading dose; MEASURE 4 data include self-administered secukinumab with a subcutaneous loading dose. Week 16 data for all MEASURE trials was analyzed using non-responder imputation. MEASURE I data from Week 52 onwards are reported from patients who entered the three-year extension study after the initial two-year study. MEASURE I-3 data from Week 52 onwards include patients who switched from placebo at Week 16 or Week 24, reported as observed. MEASURE 4 data include only patients originally randomized to secukinumab $150 \mathrm{mg}$, analyzed using multiple imputation.

Abbreviations: ASAS, Assessment of SpondyloArthritis international Society response criteria.

the MEASURE 3 trial, with a greater proportion of patients receiving the higher dose achieving ASAS20 at this time point $(150 \mathrm{mg}, 68.2 \% ; 300 \mathrm{mg}, 75.0 \%) .{ }^{52}$
Similar results were seen for the ASAS40 response rate, implying valuable reductions in patients' pain and inflammation and improvements in their physical function. In MEASURE 1 and 2, ASAS40 response rates were significantly higher with secukinumab $150 \mathrm{mg}$ compared with placebo at Week 16 (MEASURE 1: $42 \%$ versus 13\%; MEASURE 2: $36 \%$ versus $11 \%$, both $\mathrm{p}<0.001) .{ }^{15}$ This response was maintained, with $64.5 \%$ of patients reaching the ASAS40 threshold after 5 years of treatment in MEASURE 1 and 54.2\% in MEASURE $2 .{ }^{37,51}$ Likewise, a significantly higher proportion of patients in MEASURE 3 receiving secukinumab $300 \mathrm{mg}$ and secukinumab $150 \mathrm{mg}$ achieved ASAS40 at Week 16 compared with those receiving placebo ( $42.1 \%$ and $40.5 \%$ versus $21.1 \%$, respectively; $p$ $<0.05) .{ }^{16}$ Once again, this response was sustained over 3 years, with the higher dose generating a greater response (150 mg, 47.7\%; $300 \mathrm{mg}, 56.5 \%) .{ }^{52}$ ASAS20 and ASAS40 responses were seen in both anti-TNF-naïve and anti-TNFIR patients, although greater ASAS40 responses were observed in patients with no prior anti-TNF exposure (MEASURE 2: Week 260, $150 \mathrm{mg}, 63.2 \%$ versus $34.6 \%$, respectively; MEASURE 3: Week $156,300 \mathrm{mg}, 60.0 \%$ versus $41.2 \%$, respectively). ${ }^{37,51,52}$

The higher hurdle criteria for ASAS partial remission (PR), which defines a state of very low disease activity, is sometimes measured in clinical trials. Remission is a major

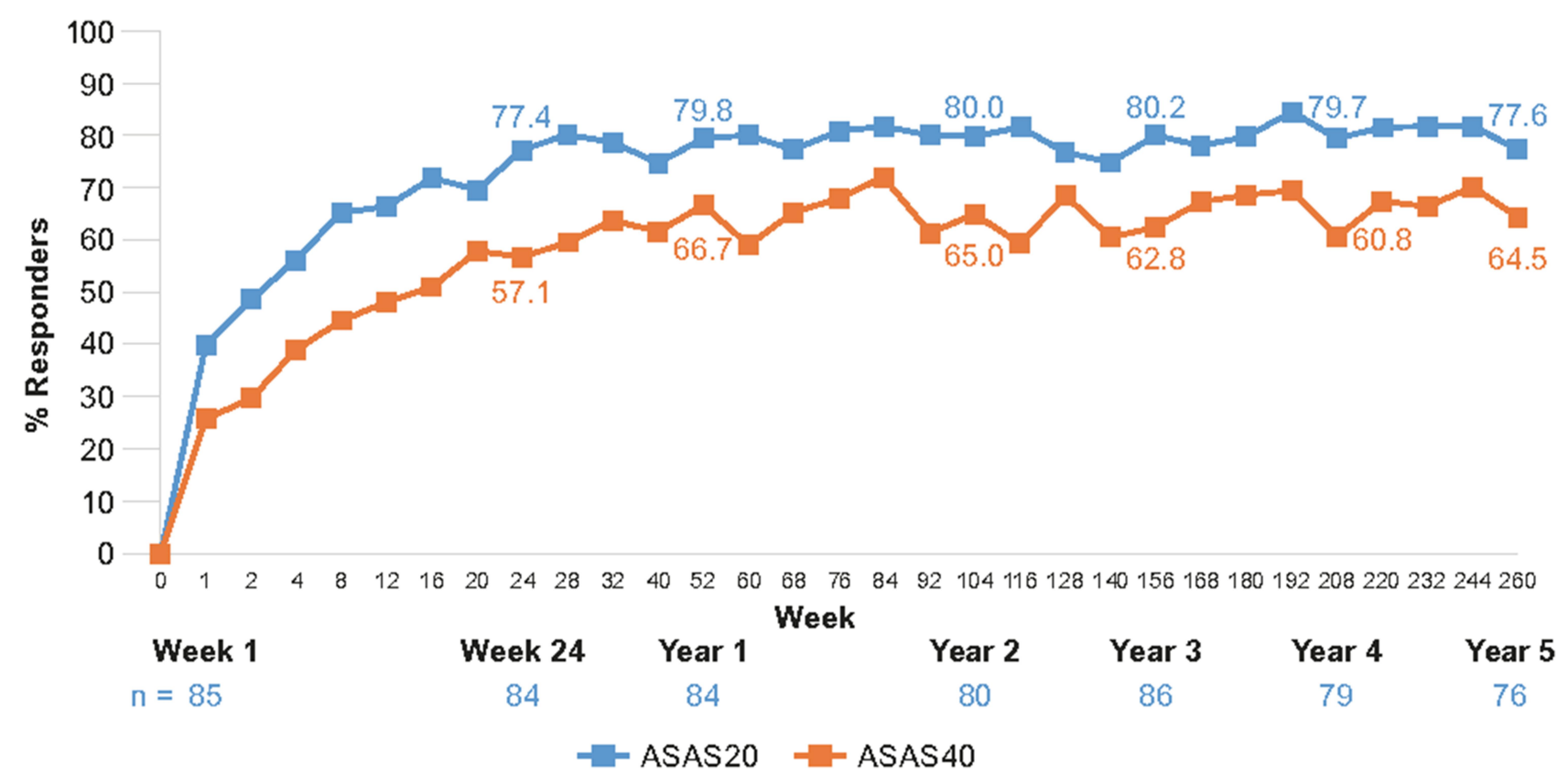

Figure 3 ASAS20 and ASAS40 line graphs showing response rates with secukinumab $150 \mathrm{mg}$ through 5 years in MEASURE I. ${ }^{37}$

Notes: Data shown are as observed through 5 years for patients who entered the three-year extension study after the initial two-year study, and do not include placebo switchers or patients whose dose was escalated. Reproduced from Baraliakos X et al. Long-term efficacy andsafety of secukinumab I50 mg in ankylosing spondylitis: 5 yearresults from the phase III MEASURE I extension study. RMD Open. 2019;5(2):e001005, () 2019. With permission from BMJ Publishing Group Ltd.

Abbreviations: ASAS, Assessment of SpondyloArthritis international Society response criteria. 
therapeutic goal for any chronic disease, and as biologic therapies for AS have become available this has become a more feasible vision for AS treatment. As true remission of AS remains an evasive and undefined goal, a surrogate measure of partial remission is used; although this falls short of true remission, partial remission is still a highly desirable outcome for patients. ${ }^{57}$ To fulfil this stringent criteria, a value of 2 or less should be present in the four domains of the ASAS response criteria. ${ }^{56}$ In MEASURE 1 and 3, ASAS PR rates were significantly higher for secukinumab $150 \mathrm{mg}$ and secukinumab $300 \mathrm{mg}$, respectively, compared with placebo at Week 16 (MEASURE 1: 15\% versus 3\% [p < 0.01]; MEASURE 3: $21 \%$ versus $1 \%[\mathrm{p}<$ 0.05]). ${ }^{15,16}$ However, the threshold of statistical significance was not met in MEASURE 2 at Week 16 (secukinumab $150 \mathrm{mg}, 14 \%$ versus placebo, $4 \%$ ). ${ }^{15}$ Nevertheless, the ASAS PR rates improved over time; in MEASURE 1 and 2, the ASAS PR rates increased over 5 years irrespective of prior anti-TNF therapies, reaching $34.8 \%$ and $25.3 \%$ of patients in PR, respectively. ${ }^{37,51}$ In MEASURE 3, the proportion of patients achieving ASAS PR after 3 years of treatment with secukinumab $300 \mathrm{mg}(28.3 \%)$ was nearly double that for secukinumab $150 \mathrm{mg}(15.9 \%){ }^{52}$

\section{Subgroup Analyses}

The efficacy of secukinumab in improving PROs has also been shown to differ between various subgroups of patients. The relative efficacy of secukinumab has been assessed with regard to prior exposure to anti-TNF therapy, the time since patient's diagnosis, patient's baseline inflammation (quantified by their C-reactive protein [CRP] levels), disease duration and patient's age.

As detailed earlier in this review, treatment with secukinumab offered important benefits in all PROs, regardless of whether patients had previously received anti-TNF therapy or not, although improvements in fatigue, pain, health-related QoL and ASAS response were generally greater in anti-TNF-naïve patients. The reason(s) behind this remains unclear. Whether prior exposure to biologics changes the course of disease, or if it changes the patient's perspectives regarding the impact of subsequent therapies on their symptoms, or if it simply reflects a more refractory population remains an area for further research.

According to a pooled analysis from MEASURE 1, 2 and 4, secukinumab provides significant health-related QoL benefits, evidenced by reduced SF-36 PCS and MCS scores, regardless of the time since AS diagnosis. Improvements were more prominent in patients diagnosed more recently $(<2$ years) compared with patients diagnosed longer ago ( $\geq 2$ years). ${ }^{58}$ Age has also been established as a predictor of treatment response in AS; on average, younger patients are more likely to display a robust response to treatment. ${ }^{59-61}$ In an analysis including data pooled from MEASURE 1-4, treatment with secukinumab $150 \mathrm{mg}$ or $300 \mathrm{mg}$ led to rapid and sustained improvements in PROs such as SF-36 and VAS back pain scores at Week 16. This was observed irrespective of disease duration, but a trend towards greater responses was evident in those with shorter disease duration. Younger patients also demonstrated superior responses, likely as a result of a shorter disease duration and a higher proportion being anti-TNF-naïve. ${ }^{62}$ With respect to disease duration and time since diagnosis, these analyses emphasize the importance of early AS treatment in improving patient outcomes.

CRP is a biochemical marker of inflammation, upregulated in chronic inflammatory conditions such as AS. It has previously been identified as a predictor of response to treatment (anti-TNF therapies) in AS, with patients more likely to demonstrate a clinically important improvement if they show higher CRP levels at baseline. ${ }^{59}$ The influence of baseline CRP levels on the efficacy of secukinumab treatment has been analyzed with respect to PROs relating to pain and fatigue. In an analysis of data from MEASURE 2, secukinumab was shown to reduce total and nocturnal back pain scores regardless of baseline high-sensitivity CRP (hsCRP) levels. Improvements were seen more rapidly with the elevated hsCRP group, by Week 1 compared with placebo (total back pain, $\mathrm{p}<0.01$; nocturnal back pain, $\mathrm{p}<$ 0.0001), in comparison with Week 4 for the normal hsCRP group (total and nocturnal back pain, $\mathrm{p}<0.01$ ); however, the degree of improvement was similar at Week 16 and sustained or further improved over 2 years in both groups. ${ }^{26}$ In the same study, FACIT-F scores were analyzed and significant improvement was seen for the normal hsCRP group ( $\mathrm{p}$ $<0.001$ versus placebo) and elevated hsCRP group $(\mathrm{p}<0.01$ versus placebo) by Week 8 . After 2 years of treatment, a greater magnitude of improvement was reported in the FACIT-F scores of the elevated hsCRP group (12.9) than the normal hsCRP group (8.3). ${ }^{26}$ Improvements were also seen in the composite ASAS20/40 response criteria with secukinumab $150 \mathrm{mg}$ versus placebo regardless of baseline CRP levels, but with more prominent responses in patients with elevated CRP (pooled MEASURE 1 and 2 analysis). ${ }^{63}$ These data suggest patients with a higher baseline level of inflammation may benefit more in terms of PROs from 
secukinumab treatment, although improvements are consistently seen regardless.

\section{Real-World Evidence}

While RCTs have demonstrated the clinical efficacy and safety of secukinumab in patients with AS in a clinical trial setting, there remains a clear need to verify effectiveness, sustainability, and safety data in a real-world setting, particularly with respect to PROs. Real-world studies expand the clinical picture, often recording a mixture of the PROs typically used in RCTs, such as the BASDAI, and more holistic measures evaluating general health and wellbeing, such as the ASAS Health Index (ASAS-HI). As secukinumab was approved for use in 2016, real-world data are currently scarce but are actively being collected through a number of studies and registries, including AQUILA, EuroSpA, CORRONA and SERENA.

AQUILA is an ongoing, multicenter, prospective noninterventional study evaluating real-world evidence in treatment of patients with AS and psoriatic arthritis (PsA), based in Germany. An interim analysis of 311 patients with AS (178 of whom have completed 52 weeks), reported in 2019, shows secukinumab reduced disease activity and improved QoL as assessed by physician and patient reported outcomes. ${ }^{64}$ The PROs being recorded as part of this study include: the BASDAI score; the ASAS-HI, which reports on aspects of patients' functioning, disability and health; ${ }^{65}$ the Medical Outcomes Study (MOS) sleep scale, which quantifies patients' sleep quality; ${ }^{66}$ and the Beck Depression Inventory-II (BDI-II) score, a widely used psychometric test that evaluates symptoms of depression. ${ }^{67}$ Amongst the patients assessed, the mean BASDAI value reduced from 5.6 at baseline to 4.0 at Week 52, in concordance with the results seen in the RCTs. The mean ASAS-HI value also decreased, from 8.2 at baseline to 6.3 at Week 52, representing an improvement in patients' health in relation to the frequently quantified aspects such as physical function and mobility, and less often addressed self-care and leisure activities. Moreover, fewer patients were suffering with mild to severe depression at Week 52 compared with at baseline; this corresponded to a decrease in the BDI-II, from 13.0 at baseline to 10.6 at Week 52. There was no reported change in the MOS sleep scale, although few baseline scores were available. $^{64}$

The EuroSpA research network is a collaborative effort among rheumatologists from 15 European countries that have SpA registries, aiming to generate real-world evidence effectiveness and safety data in $\mathrm{SpA}$. In a recent study, data were pooled from 12 countries in this network including 1,556 patients with axSpA; ${ }^{68}$ examination of this population revealed a higher proportion of patients included had previously been treated with biologics and had a longer average disease duration than in the RCT setting. Nevertheless, the data demonstrated improved BASDAI and ASDAS, a composite measure to assess disease activity with patient-reported elements, ${ }^{69}$ scores with secukinumab. A BASDAI score of $<4$, a threshold for low disease activity, was achieved by $49 \%$ of patients treated with secukinumab, whilst $9 \%$ of patients reached the more challenging threshold for ASDAS inactive disease $(<1.3){ }^{68}$

The Consortium of Rheumatology Researchers of North America (CORRONA) database, based in the USA, collects clinical information across a range of rheumatic and autoimmune diseases, and monitors PROs (amongst other measures) in these populations longitudinally. The CORRONA PsA/SpA registry exists as part of this database. To date, data have been published from 106 patients with AS, of whom 26 initiated secukinumab and the rest initiated other biologic treatments. In the patients receiving secukinumab, there were a higher proportion with a history of prior biologic use compared with patients initiating other biologics. The study reported no significant differences observed between patients who initiated secukinumab and those who initiated other biologics in terms of measures of PROs such as disease activity, QoL, and work productivity (ASDAS, BASDAI and BASFI scores, patient global assessment, pain and fatigue VAS, and WPAI) at baseline. ${ }^{70}$ No data has yet been published on the change from baseline of these measures.

SERENA is an ongoing, longitudinal, non-interventional study designed to collect prospective and retrospective data on the real-world retention, safety and effectiveness of secukinumab in treating patients with psoriasis, PsA and AS. This study is based in Europe, being conducted across approximately 400 sites, and is expected to collect data over 5 years from nearly 2,700 patients. SERENA will report on several PROs in AS, including BASDAI score, patient's global assessment, total pain and FACIT-F score. ${ }^{71}$

Several other small-scale observational and survey-based studies have been published, evaluating the effectiveness of secukinumab in a real-world setting, although a detailed discussion of their results is outside the scope of the present review. ${ }^{72-77}$ It is noteworthy that much of the real-world data 
published to date are from the use of secukinumab in patients who have failed (sometimes multiple) anti-TNF therapies. Thus, it is important to interpret these data in the context of this hard-to-treat population. Nonetheless, the data available so far indicates that the effectiveness of secukinumab in improving PROs in a real-world setting will match that seen in RCTs, and these studies are expected to provide valuable insights in coming years.

\section{Limitations of this Review}

This focus of this review was on the impact of secukinumab on PROs in AS. While there is a wealth of data regarding the efficacy and safety of secukinumab in this population, there has been less information in the patients with the non-radiographic form of axSpA, nr-axSpA. A recent study of secukinumab in patients with nr-axSpA, the PREVENT trial, has demonstrated that secukinumab $150 \mathrm{mg}$ improves disease activity measures and improves health-related QoL through 1 year versus placebo. ${ }^{78}$ Longer-term data and information on additional important PROs such a pain and fatigue are awaited from this study. Patients with PsA may also have axial symptoms. Recent data from the MAXIMISE study demonstrate that ASAS20 responses were significantly improved with secukinumab versus placebo at Week 12, with improvements sustained through 1 year. $^{79}$ As more data are published with regards to the impact of secukinumab on PROs in these populations then so we will have a more complete picture of the role of secukinumab in alleviating disease burden across the spectrum of patients with axial manifestations of spondyloarthritis.

\section{Conclusions}

It is evident that AS has a significant impact at the patient level. Pain and fatigue are the most commonly reported symptoms by patients with AS and coupled with the resultant reduction in mobility and function, can lead to significant impairments in QoL and work productivity. PROs provide important evaluations of outcomes that are most important to patients: pain, fatigue, function and independence, including their ability to work. Thus, assessing and treating PROs early is an important aspect of AS management. Evidence suggests that secukinumab can minimize the impact of AS, tangibly enhancing patient's lives; it has been shown to significantly improve a range of PROs in patients with AS, including general and diseasespecific measures of QoL, total back pain, nocturnal back pain and FACIT-F, as well as objective measures with patient-reported elements such as the ASAS response criteria, BASDAI and BASFI. A greater magnitude of response in several of these PROs was generally observed in patients who were anti-TNF-naïve, had shorter disease duration, were younger, or had higher levels of inflammation at baseline. The 300-mg dose of secukinumab, recently approved as an uptitrated dose, also showed numerically greater improvements than $150 \mathrm{mg}$, offering an option in cases of inadequate response to secukinumab $150 \mathrm{mg}$.

Treatment with secukinumab therefore offers important benefits for patients' wellbeing, including improvements in their QoL, ability to work, and reductions in pain and fatigue. Whilst this has been proven in the context of RCTs, real-world evidence is currently scarce, consisting of small-scale observational studies and some initial results from studies and registries such as AQUILA, EuroSpA and CORRONA. However, these studies indicate that the effectiveness of secukinumab in clinical practice is similar to in RCTs, despite a challenging-totreat population. Real-world evidence continues to be gathered to determine the effectiveness of secukinumab in a real-world setting.

\section{Acknowledgments}

Medical writing support was provided by Phoebe Tate and Chris Strutynskyj-Stannard of Seren Communications, an Ashfield Company, part of UDG Healthcare, the funding for which was provided by Novartis.

\section{Disclosure}

$\mathrm{AC}$ reports consultancy and speaker fees from Novartis, outside the submitted work; HT reports consultancy fees from Novartis, outside the submitted work; AM reports speaker fees from Novartis, outside the submitted work. The authors report no other potential conflicts of interest for this work.

\section{References}

1. van der Linden S, Valkenburg HA, Cats A. Evaluation of diagnostic criteria for ankylosing spondylitis. A proposal for modification of the New York criteria. Arthritis Rheum. 1984;27(4):361-368. doi:10.1002/ art.1780270401

2. van der Heijde D, Ramiro S, Landewe R, et al. 2016 update of the ASAS-EULAR management recommendations for axial spondyloarthritis. Ann Rheum Dis. 2017;76(6):978-991. doi:10.1136/annrheumdis-2016-210770 
3. Braun J, Kiltz U, Heldmann F, Baraliakos X. Emerging drugs for the treatment of axial and peripheral spondyloarthritis. Expert Opin Emerg Drugs. 2015;20(1):1-14. doi:10.1517/14728214.2015.993378

4. Glatigny S, Fert I, Blaton MA, et al. Proinflammatory Th17 cells are expanded and induced by dendritic cells in spondylarthritis-prone HLA-B27-transgenic rats. Arthritis Rheum. 2012;64(1):110-120. doi:10.1002/art.33321

5. Shen H, Goodall JC, Hill Gaston JS. Frequency and phenotype of peripheral blood Th17 cells in ankylosing spondylitis and rheumatoid arthritis. Arthritis Rheum. 2009;60(6):1647-1656. doi:10.1002/art.24568

6. Kenna TJ, Davidson SI, Duan R, et al. Enrichment of circulating interleukin-17-secreting interleukin-23 receptor-positive gamma/delta $\mathrm{T}$ cells in patients with active ankylosing spondylitis. Arthritis Rheum. 2012;64(5):1420-1429. doi:10.1002/art.33507

7. McGonagle DG, McInnes IB, Kirkham BW, Sherlock J, Moots R. The role of IL-17A in axial spondyloarthritis and psoriatic arthritis: recent advances and controversies. Ann Rheum Dis. 2019;78 (9):1167-1178. doi:10.1136/annrheumdis-2019-215356

8. Smith JA, Colbert RA. The interleukin-23/interleukin-17 axis in spondyloarthritis pathogenesis: Th17 and beyond. Arthritis Rheumatol. 2014;66(2):231-241. doi:10.1002/art.38291

9. Gravallese EM, Schett G. Effects of the IL-23-IL-17 pathway on bone in spondyloarthritis. Nat Rev Rheumatol. 2018;14(11):631640. doi:10.1038/s41584-018-0091-8

10. Jo S, Wang SE, Lee YL, et al. IL-17A induces osteoblast differentiation by activating JAK2/STAT3 in ankylosing spondylitis. Arthritis Res Ther. 2018;20(1):115. doi:10.1186/s13075-018-1582-3

11. Pinto LG, Cunha TM, Vieira SM, et al. IL-17 mediates articular hypernociception in antigen-induced arthritis in mice. Pain. 2010;148(2):247-256. doi:10.1016/j.pain.2009.11.006

12. McNamee KE, Alzabin S, Hughes JP, et al. IL-17 induces hyperalgesia via TNF-dependent neutrophil infiltration. Pain. 2011;152 (8):1838-1845. doi:10.1016/j.pain.2011.03.035

13. U.S. Food and Drug Administration (FDA). Secukinumab prescribing information. Available from: http://www.accessdata.fda.gov/drug satfda_docs/label/2020/125504s035lbl.pdf. Accessed October 20, 2020.

14. European Medicines Agency (EMA). Secukinumab summary of product characteristics. Available from: http://www.ema.europa.eu/docs/ en_GB/document_library/EPAR_-_Product_Information/human/ 003729/WC500183129.pdf. Accessed September 20, 2020.

15. Baeten D, Sieper J, Braun J, et al. Secukinumab, an interleukin-17A inhibitor, in ankylosing spondylitis. $N$ Engl $J$ Med. 2015;373 (26):2534-2548. doi:10.1056/NEJMoa1505066

16. Pavelka K, Kivitz A, Dokoupilova E, et al. Efficacy, safety, and tolerability of secukinumab in patients with active ankylosing spondylitis: a randomized, double-blind phase 3 study, MEASURE 3. Arthritis Res Ther. 2017;19(1):285. doi:10.1186/s13075-017-1490-y

17. Kivitz AJ, Wagner U, Dokoupilova E, et al. Efficacy and safety of secukinumab $150 \mathrm{mg}$ with and without loading regimen in ankylosing spondylitis: 104-week results from MEASURE 4 Study. Rheumatology Therapy. 2018;5(2):447-462. doi:10.1007/s40744018-0123-5

18. Huang F, Sun F, Wan W, et al. Secukinumab provided significant and sustained improvement in the signs and symptoms of ankylosing spondylitis: results from the 52-week, Phase III China-centric study, MEASURE 5. Clin Med J. 2020. doi:10.1097/CM9.0000000 000001099

19. Kishimoto M, Taniguchi A, Fujishige A, et al. Efficacy and safety of secukinumab in Japanese patients with active ankylosing spondylitis: 24-week results from an open-label phase 3 study (MEASURE 2-J). Modern Rheumatology. 2020;30(1):132-140. doi:10.1080/143975 95.2018.1538004

20. ClinicalTrials.gov. NCT03259074: effect of secukinumab on radiographic progression in ankylosing spondylitis as compared to GP2017 (Adalimumab Biosimilar) (SURPASS). Available from: https://clinical trials.gov/ct2/show/NCT03259074. Accessed January 03, 2020.
21. Cohen SB, Strand V, Aguilar D, Ofman JJ. Patient- versus physicianreported outcomes in rheumatoid arthritis patients treated with recombinant interleukin-1 receptor antagonist (anakinra) therapy. Rheumatol. 2004;43(6):704-711. doi:10.1093/rheumatology/keh152

22. Strand V, Cohen S, Crawford B, Scott DL. Patient-reported outcomes better discriminate active treatment from placebo in randomized controlled trials in rheumatoid arthritis. Rheumatol. 2004;43 (5):640-647. doi:10.1093/rheumatology/keh140

23. Ward MM, Deodhar A, Akl EA, et al. American College of Rheumatology/Spondylitis association of america/spondyloarthritis research and treatment network 2015 recommendations for the treatment of ankylosing spondylitis and nonradiographic axial spondyloarthritis. Arthritis Rheumatol. 2016;68(2):282-298. doi:10.1002/ art.39298

24. Landewé R, van Tubergen A. Clinical tools to assess and monitor spondyloarthritis. Curr Rheumatol Rep. 2015;17(7):47. doi:10.1007/ s11926-015-0522-3

25. Yellen SB, Cella DF, Webster K, Blendowski C, Kaplan E. Measuring fatigue and other anemia-related symptoms with the Functional Assessment of Cancer Therapy (FACT) measurement system. J Pain Symptom Manage. 1997;13(2):63-74. doi:10.1016/ S0885-3924(96)00274-6

26. Deodhar A, Conaghan PG, Kvien TK, et al. Secukinumab provides rapid and persistent relief in pain and fatigue symptoms in patients with ankylosing spondylitis irrespective of baseline C-reactive protein levels or prior tumour necrosis factor inhibitor therapy: 2-year data from the MEASURE 2 study. Clin Exp Rheumatol. 2019;37 (2):260-269.

27. Sieper J, Rudwaleit M, Baraliakos X, et al. The Assessment of SpondyloArthritis international Society (ASAS) handbook: a guide to assess spondyloarthritis. Ann Rheum Dis. 2009;68(Suppl 2):ii144. doi:10.1136/ard.2008.104018

28. Doward LC, Spoorenberg A, Cook SA, et al. Development of the ASQoL: a quality of life instrument specific to ankylosing spondylitis. Ann Rheum Dis. 2003;62(1):20-26. doi:10.1136/ard.62.1.20

29. Rabin R, de Charro F. EQ-5D: a measure of health status from the EuroQol Group. Ann Med. 2001;33:337-343. doi:10.3109/0785389 0109002087

30. Ware JE Jr, Sherbourne CD, The MOS. 36-item short-form health survey (SF-36). I. Conceptual framework and item selection. Med Care. 1992;30(6):473-483. doi:10.1097/00005650-19920600000002

31. Reilly MC, Zbrozek AS, Dukes EM. The validity and reproducibility of a work productivity and activity impairment instrument. PharmacoEconomics. 1993;4(5):353-365. doi:10.2165/00019053199304050-00006

32. Garrett S, Jenkinson T, Kennedy LG, Whitelock H, Gaisford P, Calin A. A new approach to defining disease status in ankylosing spondylitis: the bath ankylosing spondylitis disease activity index. $J$ Rheumatol. 1994;21(12):2286-2291.

33. Calin A, Garrett S, Whitelock H, et al. A new approach to defining functional ability in ankylosing spondylitis: the development of the bath ankylosing spondylitis functional index. J Rheumatol. 1994;21 (12):2281-2285.

34. Jenkinson TR, Mallorie PA, Whitelock HC, Kennedy LG, Garrett SL, Calin A. Defining spinal mobility in ankylosing spondylitis (AS). The Bath AS Metrology Index. J Rheumatol. 1994;21(9):1694-1698.

35. Aissaoui N, Rostom S, Hakkou J, et al. Fatigue in patients with ankylosing spondylitis: prevalence and relationships with diseasespecific variables, psychological status, and sleep disturbance. Rheumatol Int. 2012;32(7):2117-2124. doi:10.1007/s00296-0111928-5

36. Heiberg T, Lie E, van der Heijde D, Kvien TK. Sleep problems are of higher priority for improvement for patients with ankylosing spondylitis than for patients with other inflammatory arthropathies. Ann Rheum Dis. 2011;70(5):872-873. doi:10.1136/ard.2010.133793 
37. Baraliakos X, Braun J, Deodhar A, et al. Long-term efficacy and safety of secukinumab $150 \mathrm{mg}$ in ankylosing spondylitis: 5-year results from the phase III MEASURE 1 extension study. RMD Open. 2019;5(2):e001005. doi:10.1136/rmdopen-2019-001005

38. Deodhar AA, Dougados M, Baeten DL, et al. Effect of secukinumab on patient-reported outcomes in patients with active ankylosing spondylitis: a phase III randomized trial (MEASURE 1). Arthritis Rheumatol. 2016;68(12):2901-2910. doi:10.1002/art.39805

39. Cella D, Yount S, Sorensen M, Chartash E, Sengupta N, Grober J. Validation of the functional assessment of chronic illness therapy fatigue scale relative to other instrumentation in patients with rheumatoid arthritis. J Rheumatol. 2005;32(5):811-819.

40. Kvien T, Conaghan PG, Deodhar A, et al. Reduction in fatigue in patients with active ankylosing spondylitis: results of two phase 3 studies of secukinumab. Poster SAT0421 presented at the European League Against Rheumatism (EULAR) Annual European Congress of Rheumatology; 8-11 June 2016.; London, UK. 2016.

41. Bodur H, Ataman S, Rezvani A, et al. Quality of life and related variables in patients with ankylosing spondylitis. Qual Life Res. 2011;20(4):543-549. doi:10.1007/s11136-010-9771-9

42. Marzo-Ortega H, Miceli-Richard C, Gill S, et al. Subcutaneous secukinumab $150 \mathrm{mg}$ provides rapid and sustained relief in total and nocturnal back pains, morning stiffness, and fatigue in patients with active ankylosing spondylitis over 4 years. Arthritis Rheumatol. 2019;71.

43. Ward MM. Health-related quality of life in ankylosing spondylitis: a survey of 175 patients. Arthritis Care Res (Hoboken). 1999;12 (4):247-255. doi:10.1002/1529-0131(199908)12:4<247::AIDART3>3.0.CO;2-H

44. Emery P, Baeten D, Deodhar A, et al. Secukinumab improves physical function and quality of life in patients with active ankyloising spondylitis: 2-year data from MEASURE 1, a Phase 3 randomised trial. Ann Rheum Dis. 2016;75:818. doi:10.1136/annrheumdis-2016eular. 2308

45. Deodhar A, Boonen A, Ferraccioli G, et al. Secukinumab provides early and sustained improvements in health-related quality of life in patients with ankylosing spondylitis: a pooled analysis from the secukinumab phase 3 trial program. Arthritis Rheumatol. 2018;70.

46. Boonen A, Chorus A, Miedema H, et al. Withdrawal from labour force due to work disability in patients with ankylosing spondylitis. Ann Rheum Dis. 2001;60(11):1033-1039. doi:10.1136/ ard.60.11.1033

47. Rudwaleit M, Haibel H, Baraliakos X, et al. The early disease stage in axial spondylarthritis: results from the German Spondyloarthritis Inception Cohort. Arthritis Rheum. 2009;60(3):717-727. doi:10.1002/ art. 24483

48. Boonen A. van der Linden SM. The burden of ankylosing spondylitis. J Rheumatol Suppl. 2006;78:4-11.

49. Deodhar A, Conaghan PG, Strand V, et al. Secukinumab provides sustained improvements in work productivity and health related quality of life in patients with ankylosing spondylitis: long-term results from MEASURE 1 and MEASURE 2. Ann Rheum Dis. 2017;76:1293.

50. Rudwaleit M, Listing J, Brandt J, Braun J, Sieper J. Prediction of a major clinical response (BASDAI 50) to tumour necrosis factor alpha blockers in ankylosing spondylitis. Ann Rheum Dis. 2004;63(6):665670. doi:10.1136/ard.2003.016386

51. Marzo-Ortega H, Sieper J, Kivitz A, et al. Long-term evaluation of secukinumab $150 \mathrm{mg}$ in ankylosing sponylitis: 5-year end-of-study efficacy and safety results from a phase 3 trial. Ann Rheum Dis. 2019;78:873.

52. Pavelka K, Kivitz AJ, Dokoupilova E, et al. Secukinumab 150/300 $\mathrm{mg}$ provides sustained improvements in the signs and symptoms of active ankylosing spondylitis: 3-year results from the phase 3 MEASURE 3 Study. ACR Open Rheumatology. 2020;1-9.
53. Zochling J. Measures of symptoms and disease status in ankylosing spondylitis: ankylosing Spondylitis Disease Activity Score (ASDAS), Ankylosing Spondylitis Quality of Life Scale (ASQoL), Bath Ankylosing Spondylitis Disease Activity Index (BASDAI), Bath Ankylosing Spondylitis Functional Index (BASFI), Bath Ankylosing Spondylitis Global Score (BAS-G), Bath Ankylosing Spondylitis Metrology Index (BASMI), Dougados Functional Index (DFI), and Health Assessment Questionnaire for the Spondylarthropathies (HAQ-S). Arth Care Res. 2011;63:S47S58.

54. Wei JCC, Baeten D, Geusens P, Porter B, Martin R, Richards H. Intravenous loading and subcutaneous maintenance with secukinumab provides sustained improvement in multiple measures of disease activity in subjects with active ankyloisng spondylitis: 52-week data from the randomized, double-blind, placebo-controlled, phase 3 measure 1 study. Ann Rheum Dis. 2015;74:1146-1147.

55. Anderson JJ, Baron G, van der Heijde D, Felson DT, Dougados M. Ankylosing spondylitis assessment group preliminary definition of short-term improvement in ankylosing spondylitis. Arthritis Rheum. 2001;44(8):1876-1886. doi:10.1002/1529-0131(200108)44:8<1876:: AID-ART326>3.0.CO;2-F

56. Brandt J, Listing J, Sieper J, Rudwaleit M, Van der Heijde D, Braun J. Development and preselection of criteria for short term improvement after anti-TNFa treatment in ankylosing spondylitis. Ann Rheum Dis. 2004;63:1438-1444. doi:10.1136/ard.2003.016717

57. Zochling J, Braun J. Remission in ankylosing spondylitis. Clin Exp Rheumatol. 2006;24(6 Suppl 43):S-88-92.

58. Deodhar A, Boonen A, Ferraccioli G, et al. Secukinumab improves health-related quality of life in patients with ankylosing spondylitis, irrespective of time since first diagnosis: pooled results from the secukinumab phase 3 trial program. Ann Rheum Dis. 2019;78:878-879.

59. Vastesaeger N, van der Heijde D, Inman R, et al. Predicting the outcome of ankylosing spondylitis therapy. Ann Rheum Dis. 2011;70:973-981. doi:10.1136/ard.2010.147744

60. Arends S, Brouwer E, Van der Veer E, et al. Baseline predictors of response and discontinuation of tumor necrosis factor-alpha blocking therapy in ankylosing spondylitis: a prospective longitudinal observational cohort study. Arthritis Res Ther. 2011;13:R94. doi:10.1186/ $\operatorname{ar} 3369$

61. Rudwaleit M, Claudepierre P, Wordsworth P, et al. Effectiveness, safety, and predictors of good clinical response in 1250 patients treated with adalimumab for active ankylosing spondylitis. $J$ Rheumatol. 2009;36(4):801-808. doi:10.3899/jrheum.081048

62. Deodhar A, Mease P, Machado P, Meng X, Strand V, Magrey M. Impact of age and disease duration on the response to IL-17A inhibitor (secukinumab) treatment in ankylosing spondylitis: pooled results from the phase 3 MEASURE studies. Arthritis Rheumatol. 2019;71.

63. Braun J, Deodhar A, Landewe R, et al. Impact of baseline C-reactive protein levels on the response to secukinumab in ankylosing spondylitis: 3-year pooled data from two phase III studies. RMD Open. 2018;4(2):e000749. doi:10.1136/rmdopen-2018-000749

64. Kiltz U, Peterlik D, Winkelmann V, Tony HP. Aquila study in German - real world data on secukinumab's effectiveness in ankylosing spondylitis patients - results from an interim analysis. Ann Rheum Dis. 2019;78:890.

65. Kiltz U, Van der Heijde D, Boonen A, Braun J. The ASAS Health Index (ASAS HI) - a new tool to assess the health status of patients with spondyloarthritis. Clin Exp Rheum. 2014;32(5):S-105-108.

66. Stewart AL, Hays RD, Ware JE. The MOS short-form general health survey: reliability and validity in a patient population. Med Care. 1988;26:724-732. doi:10.1097/00005650-198807000-00007

67. Beck AT, Steer RA, Brown GK. Beck Depression Inventory. second edition manual. San Antonio (TX): The Psychological Corporation; 1996. 
68. Michelson B, Brahe $\mathrm{CH}$, Askling J, et al. Pooled 6-month treatment outcomes and drug retention rates in 1556 patients with axial spondyloarthritis treated with secukinumab in routine clinical practice in 12 European countries in the EuroSpa research collaboration. Ann Rheum Dis. 2019;78:888-889.

69. Lukas C, Landewe R, Sieper J, et al. Development of an ASASendorsed disease activity score (ASDAS) in patients with ankylosing spondylitis. Ann Rheum Dis. 2009;68(1):18-24. doi:10.1136/ ard.2008.094870

70. Ogdie A, Liu M, Rebello S, et al. Clinical characteristics and treatment profiles of patients with ankylosing spondylitis who initiated secukinumab and other biologics: results from the corona psoriatic arthritis/spondyloarthritis (PsA/SpA) registry. Ann Rheum Dis. 2019;78:484-486.

71. Augustin M, Von Kiedrowski R, Rigopoulos D, et al. Effectiveness and safety of secukinumab treatment in real-world clinical settings in European countries confirms its efficacy and safety from clinical trials: data from an interim analysis of SERENA study. J Am Acad Dermatol. 2019;81(4):AB50.

72. Alkoky H, Khan Z, Tahir H. Long-term efficacy of secukinumab in the management of ankylosing spondylitis in clinical practice: real world data (Abstract E095). Rheumatol. 2019;58:kez110.093. doi:10.1093/rheumatology/kez110.093

73. Argumánez CM, Emperiale V, Martín M, et al. Secukinumab for axial spondyloarthritis: drug survival in real-world setting and response factors (Abstract FRI0402). Ann Rheum Dis. 2019;78 (Supp12):887.881-887.

74. Elliott A, Wright G. Real-world data on secukinumab use for psoriatic arthritis and ankylosing spondylitis. Ther Adv Musculoskelet Dis. 2019;11:1759720X19858510. doi:10.1177/1759720X19858510

75. Magrey M, Bozyczko M, Wolin D, et al. Treatment experience and satisfaction in ankylosing spondylitis patients treated with secukinumab: results from a us web-based survey. Ann Rheum Dis. 2018;77:1014

76. Martinis F, Caimmi A, Carletto A, Fracassi E, Rossini M. Real-world efficacy and safety of secukinumab: data from verona's cohort. Ann Rheum Dis. 2018;77:1544-1545.
77. Flouri I, Repa A, Avgustidis N, et al. Comparable clinical responses but higher treatment adherence of secukinumab compared to TNF inhibitors in spondyloarthritis patients: long term prospective observational study in a tertiary hospital of Greece. Ann Rheum Dis. 2019;78:893.

78. Deodhar A, Blanco R, Dokoupilová E, et al. Secukinumab improves signs and symptoms of non-radiographic axial spondyloarthritis: primary results of a randomized controlled phase III study. Arthritis Rheumatol. 2020. doi:10.1002/art.41477

79. Baraliakos X, Gossec L, Pournara E, et al. Secukinumab improves clinical and imaging outcomes in patients with psoriatic arthritis and axial manifestations with inadequate response to NSAIDs: week 52 results from the MAXIMISE trial. Ann Rheum Dis. 2020;79(Supp11): Abstract OPOO53.

80. Marzo-Ortega H, Sieper J, Kivitz AJ, et al. Secukinumab $150 \mathrm{mg}$ provides sustained improvements in the signs and symptoms of active ankylosing spondylitis with consistent safety profile and high retention rate: 4-Year results from a phase III trial [abstract]. Arthritis Rheumatol. 2018;70.

81. Marzo-Ortega H, Sieper J, Kivitz A, et al. Secukinumab provides sustained improvements in the signs and symptoms of active ankylosing spondylitis with high retention rate: 3-year results from the phase III trial, MEASURE 2. RMD Open. 2017;3(2):3:e000592. doi:10.1136/rmdopen-2017-000592

82. Marzo-Ortega H, Sieper J, Kivitz A, et al. Secukinumab and sustained improvement in signs and symptoms of patients with active ankylosing spondylitis through two years: results from a phase III study. Arthritis Care Res (Hoboken). 2017;69(7):1020-1029. doi:10.1002/acr.23233

83. Braun J, Sieper J, Aelion J, et al. Secukinumab improves multiple parameters of disease activity in subjects with active ankylosing spondylitis through 52 weeks of subcutaneous therapy: data from the phase 3 MEASURE 2 study. Ann Rheum Dis. 2015;74 (Supp12):1147. doi:10.1136/annrheumdis-2015-eular.3031
Open Access Rheumatology: Research and Reviews

\section{Publish your work in this journal}

Open Access Rheumatology Research and Reviews is an international, peer-reviewed, open access journal publishing original research, reports, editorials, reviews and commentaries on all aspects of clinical and experimental rheumatology in the clinic and laboratory including the following topics: Pathology, pathophysiology of rheumatological diseases; Investigation, treatment and management

\section{Dovepress}

of rheumatological diseases; Clinical trials and novel pharmacological approaches for the treatment of rheumatological disorders. The manuscript management system is completely online and includes a very quick and fair peer-review system, which is all easy to use. Visit http://www.dovepress.com/testimonials.php to read real quotes from published authors. 